\title{
An acceptable slow-release phosphate preparation
} 'Slow P'

\author{
VICTOR PARSONS \\ D.M., M.R.C.P. \\ Physician
ANDREW PORTER
M.B., M.R.C.P.
Renal Registrar

\author{
VALERIE PARSONS \\ M.Sc. \\ Biochemist \\ CHRISTOPHER LUND \\ M.B., B.S. \\ House Physician
}

Renal Unit and Department of Chemical Pathology, King's College Hospital, London, S.E.5

\begin{abstract}
Summary
Slow $\mathbf{P}$ has been an acceptable form of oral phosphate therapy in a series of patients with a variety of bone disease. Therapeutic responses have been achieved in a number of patients without side effects together with minor elevation of the serum and urinary phosphate in the majority of patients. Some patients have continued with such supplements for several months which encourages an extended trial under more stringent conditions.
\end{abstract}

\section{Introduction}

Oral phosphate therapy has been given for a variety of purposes:

(a) To raise the serum phosphate concentration in patients with renal phosphate-losing rickets or osteomalacia. This encourages the healing of the bone disease without the use of pharmacological doses of Vitamin $D_{2}$. (Wilson \& Yendt, 1962; Nagant, de Deuxchaisnes \& Krane, 1967.)

(b) To possibly hasten the healing of traumatic fractures. (Goldsmith et al., 1967.)

(c) To reduce raised plasma calcium concentrations which accompany malignant disease. (Goldsmith \& Ingbar, 1966; Thalassings \& Joplin, 1968.)

(d) To reduce the raised plasma calcium accompanying hyperparathyroidism while the patient is awaiting surgery. (Dent, 1962; Eisenberg, 1968.)

(e) To increase the excretion of urinary phosphate and indirectly pyrophosphate in the treatment of urinary calculi. (Fleish, Bisaz \& Care, 1964; Edwards, Russell \& Hodgkinson, 1965.)

(f) To enhance the activity of calcitonin. (Hirsch \& Cooper, 1968.)

The common forms of phosphate therapy include a neutral phosphate salt mixture in compressed tablet form, granules or a simple liquid; no B.P. formulation is available. The disadvantage of this type of therapy is that it gives a fluctuating blood concentration particularly at night. If the amount given is increased to achieve higher sustained plasma concentrations the patient often suffers diarrhoea from the large intermittent salt load. In the elderly, such large sodium loads may lead to fluid retention, while it is difficult to get patients to take such therapy regularly on an outpatient basis, the general rule being the more frequent the daily administration the more likely are doses to be omitted.

Tablets containing mixtures of disodium hydrogen phosphate and sodium dihydrogen phosphate may become extremely hard on storage and be passed through the bowel unabsorbed.

Because of these difficulties we thought it worthwhile to try a wax-bonded tablet of sodium dihydrogen phosphate. This type of tablet has been extensively used in potassium chloride therapy as Slow K. (Wynn, 1965.)

\section{Subjects in the trial}

Three male physicians took 8 tablets $\left(2.4 \mathrm{~g} \mathrm{PO}_{4}\right)$ at 6-hourly intervals throughout $24 \mathrm{hr}$ together with a normal diet and fluid intake. Blood samples were taken just before each oral dose and at intercalated times. Urine was voided at intervals throughout the $24 \mathrm{hr}$ and stored before analysis. A series of patients were given Slow $\mathbf{P}$ over a varying length of time; none had more than $7.2 \mathrm{~g}$ daily, the mode being $5.4 \mathrm{~g}$ (16 tablets a day). Blood was obtained either as outpatients or during more extensive investigation and treatment as inpatients. No attempt was made to control the dietary intake of phosphate and therapy was continued at the same time as phosphate administration. 


\section{Analytic methods}

Serum and urinary phosphate were measured by the Technicon modification of the Fiske \& Subbarow (1925) method. Serum calcium was estimated by Eppendorf photometry, alkaline phosphates by hydrolysis of thymolphthalein monophosphate (Coleman \& Stroje, 1965), total urinary hydroxyproline peptides by the method of Prockop \& Udenfriend (1960).

\section{Results}

The release rate of phosphate in simple aqueous solution at room temperature is shown in Fig. 1. $50 \%$ is released by $60 \mathrm{~min}, 75 \%$ by $90 \mathrm{~min}$.

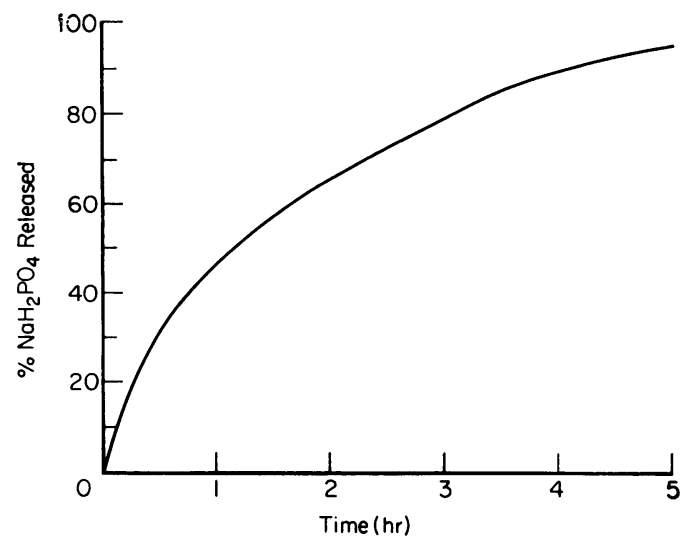

FIG. 1. The rate of release of phosphate from tablets in simple solution in water at $37^{\circ} \mathrm{C}$.

Normal volunteers: Slight epigastric discomfort was noted at the high dosage level of $9.6 \mathrm{~g} \mathrm{PO}_{4} / 24 \mathrm{hr}$ but no bowel upset. Plasma concentrations were measured and shown with the urinary excretion in Fig. 2. Throughout the 24 hours, urinary excretion

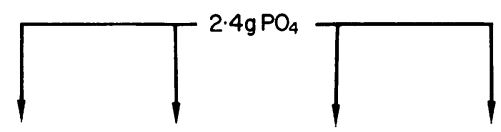

Urinary $\mathrm{PO}_{4}$ excretion

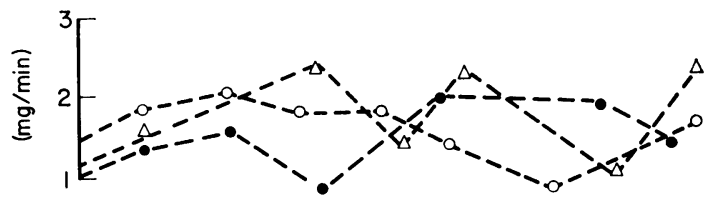

Plasma $\mathrm{PO}$
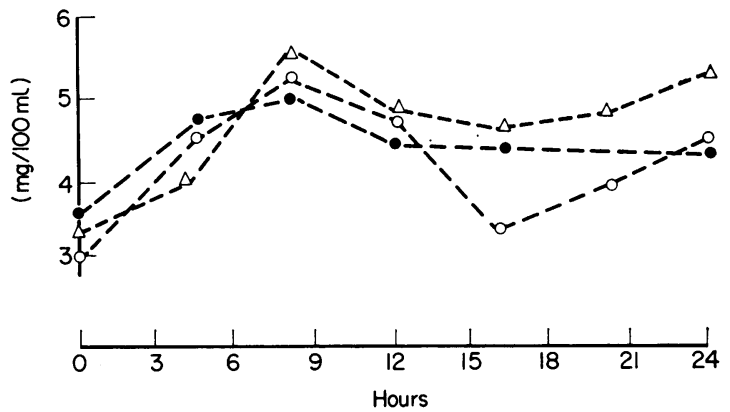

FIG. 2. Plasma phosphate concentration and urinary excretion of phosphate during the ingestion of four separate doses of slowly released acid phosphate given to three normal volunteers. C.L., $\triangle$; D.S., O; V.P., O.

ranged around $2 \mathrm{mg} \mathrm{PO}_{4} / \mathrm{min}$ indicating that only part of the gut load was excreted. The steady plasma concentrations showed that the typical diurnal rhythm (Mills \& Stanbury, 1955) has been smoothed

TABle 1. Phosphate measurements in plasma

\begin{tabular}{|c|c|c|c|c|c|}
\hline \multirow{2}{*}{ Patient, Sex, Age, Disease } & \multicolumn{2}{|c|}{$\begin{array}{l}\text { Plasma } \mathrm{PO}_{4} \mathrm{mg} / 100 \mathrm{ml} \\
\text { Mean and estimations }\end{array}$} & \multirow[b]{2}{*}{$\begin{array}{c}\text { Total Slow P } \\
\text { dosage } \\
(\mathrm{gm})\end{array}$} & \multirow{2}{*}{ Days } & \multirow[b]{2}{*}{$\begin{array}{l}\text { Other } \\
\text { treatment }\end{array}$} \\
\hline & $\begin{array}{l}\text { Pre- } \\
\text { treatment }\end{array}$ & $\begin{array}{l}\text { During } \\
\text { treatment }\end{array}$ & & & \\
\hline S.W. m. 43 Osteogenic sarcoma of femur & $3 \cdot 5(1)$ & $3 \cdot 8(14)$ & 1200 & 180 & - \\
\hline F.R. f. 33 Carcinomatosis ? primary & $3 \cdot 3(3)$ & $3 \cdot 1(10)$ & 271 & 50 & Calcitonin \\
\hline C.S. m. 49 Myeloma & $1 \cdot 1(1)$ & $2 \cdot 6(11)$ & 56 & 10 & Prednisone \\
\hline M.O. f. $70 \mathrm{Ca}$ breast & $2 \cdot 8(6)$ & $3 \cdot 6(9)$ & 270 & 40 & Calcitonin \\
\hline E.H. f. $49 \mathrm{Ca}$ breast & $3 \cdot 5(3)$ & $3 \cdot 8(3)$ & 32 & 6 & - \\
\hline T.P. f. $63 \mathrm{Ca}$ breast & $3 \cdot 4(5)$ & $5 \cdot 3(1)$ & 770 & 120 & $\begin{array}{l}\text { Durabolin } \\
\text { Prednisone }\end{array}$ \\
\hline G.E.M. m. 71 Ca prostate & $2 \cdot 1(12)$ & $3.0(9)$ & 1320 & 270 & Stilboestrol \\
\hline H.R. m. 72 Ca prostate & $2 \cdot 0(6)$ & $2 \cdot 1(5)$ & 566 & 120 & - \\
\hline R.C. m. $78 \mathrm{Ca}$ prostate & $3.4(8)$ & $3.5(8)$ & 1050 & 220 & - \\
\hline J.B. m. 46 Ca Lung & $3 \cdot 4(5)$ & $2 \cdot 7(15)$ & 3606 & 460 & Calcitonin \\
\hline R.K. f. 68 Hypernephroma & $3 \cdot 4(1)$ & $3 \cdot 5(3)$ & 288 & 40 & - \\
\hline B.D. f. 49 Hypernephroma & $2 \cdot 5(6)$ & $2 \cdot 3(8)$ & 84 & 14 & Primolut depot \\
\hline E.G. f. 79 Osteomalacia & $2 \cdot 9(4)$ & $2 \cdot 8(4)$ & 168 & 30 & Vitamin D \\
\hline F.L. f. 64 Osteomalacia & $3 \cdot 5(5)$ & $3 \cdot 6(21)$ & 960 & 160 & - \\
\hline
\end{tabular}


out. In the acute experiments the threshold for phosphate, which lies around $5.2 \mathrm{mg} / 100 \mathrm{ml}$ in subjects with normal renal function (Anderson \& Parsons, 1963), was exceeded in one or two periods in these subjects. There was no evidence for peaking of the blood concentrations after the oral doses.

In the patients studied (Table 1) many were suffering from bone pain due to malignant deposits and were receiving other forms of therapy which are known to reduce the serum phosphate such as steroids and calcitonin. Phosphate was given to encourage calcification of their pathological fractures and deposits; metabolic studies surrounding these patients will be communicated later. An opportunity was taken to give a patient E.C. phosphate supplements while under strict balance conditions in a metabolic ward. During the first period he was in negative phosphate balance; additions of $1 \mathrm{~g}$ and then $2 \mathrm{~g}$ of oral phosphate were given in subsequent periods to show how there was increased absorption from the gut, increased urinary excretion and eventually a positive balance (Fig. 3). The response to

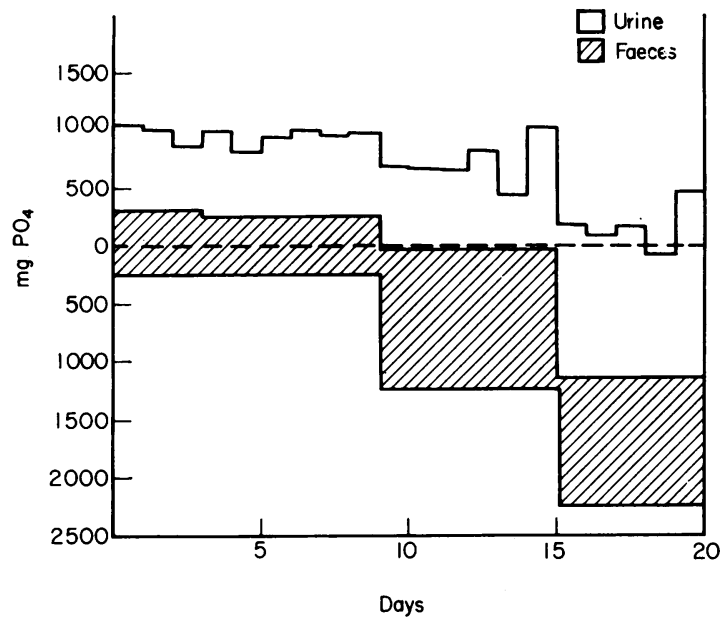

FIG. 3. Phosphate balance on patient R.C. Food and added phosphate ingestion plotted downwards $\downarrow$. Faecal and urinary excretion plotted upwards from the intake base line.

therapy can be illustrated by reference to three patients.

\section{Patients}

S.W. was thought to have a secondary deposit causing a pathological fracture of the neck of the right femur. Biopsy had shown what was thought to be an anaplastic carcinoma. After internal fixation he was given Slow $\mathbf{P}$ for a long period with massive calcification of the tumour 'metastasis', a precipitous fall in the total urinary hydroxyproline and alleviation of pain (Fig. 4). He was allowed out of hospital walking on the healed fracture, to be admitted 4 months later for a hind quarter amputation for what

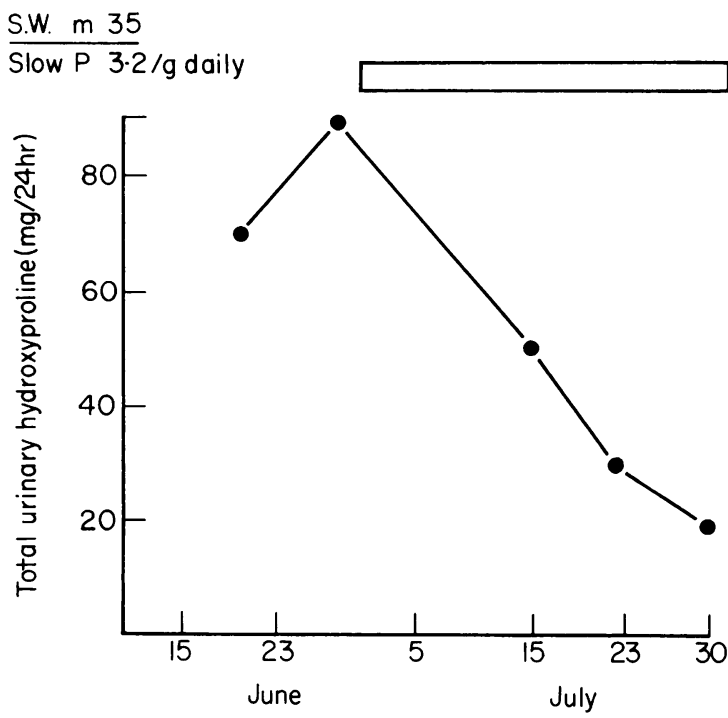

FIg. 4. Total urinary hydroxyproline peptide excretion from patient S.W. during treatment.

proved to be an anaplastic osteogenic sarcoma. The hydroxyproline excretion had returned to a high level at this time.

J.B. was suffering from widespread rheumatoid disease and was thought to have a steroid induced vertebral collapse. Biopsy, however, showed malignant deposits with an adenomatous pattern, later found to be stemming from a carcinoma of the bronchus. Despite radiotherapy his pain continued and a trial of calcitonin in a moderate dosage of 160 MRC units daily was given. Only when Slow $\mathbf{P}$ was administered were there striking changes in the serum chemistry leading to symptoms of tetany on one occasion (Fig. 5). This finding confirms the profound hypocalcaemic effects of calcitonin when combined with phosphate observed in animals (Hirsch \& Cooper, 1968) which does not occur in normocalcaemic individuals (Foster et al., 1966). Phosphate administration alone has not been observed to produce such hypocalcaemia in other normocalcaemic patients with widespread metastases.

Osteomalacia from tubular phosphate diabetes can be alleviated by the use of phosphate salts. The healing of osteomalacia is accompanied by an increase in the total urinary hydroxyproline (Anderson et al., 1968, Smith \& Dick, 1968). This was observed in patient F.L. without any extra Vitamin D supplements than was contained in a ward diet (Fig. 6). The rise is similar to that obtained in a patient with malabsorption treated by Vitamin D without phosphate supplements. 


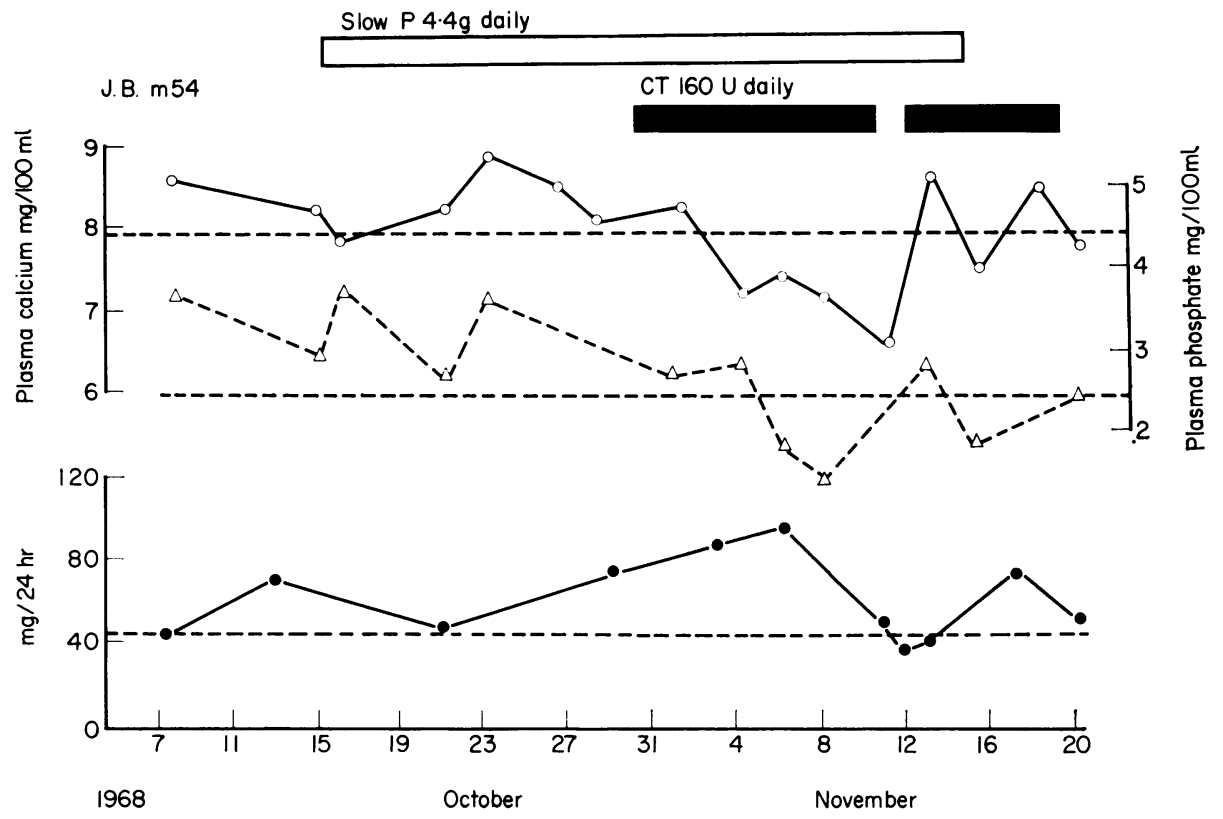

FIG. 5. Plasma calcium $(O)$ and phosphate concentrations $(\Delta)$ and urinary hydroxyproline excretion ( $O$ ) during the treatment of patient J.B. with rorcine calcitonin and phosphate supplements.

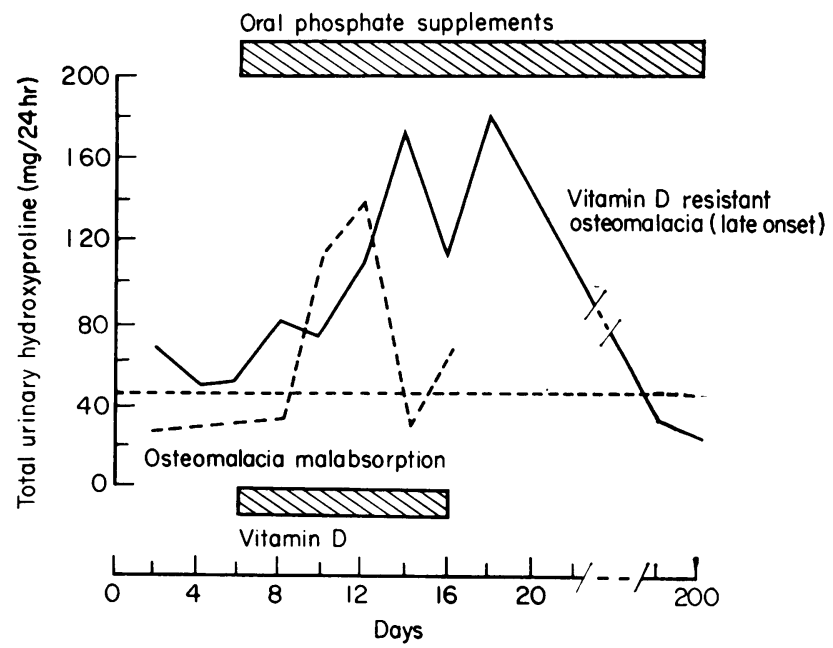

FIG. 6. Total urinary hydroxyproline excretion in two osteomalaeic patients, one F.L. treated with oral phosphate supplements and the other by Vitamin $D$.

These examples show that Slow P provides sufficient therapeutic concentrations of phosphate probably at the bone surface to achieve these changes in metabolism. The excretion of phosphate in the urine in these patients, many under treatment, did not reveal excessive losses despite rises in the plasma concentration, suggesting that many were in positive balance as far as this ion was concerned. The preparation was accepted well and some patients were able to take over a kilogram over a period of weeks without side effects, gut discomfort or diarrhoea. Only one patient, F.R., had diarrhoea which was not controlled by halving the dose and may have been more related to the radiotherapy she was receiving. 
In this preliminary trial this oral preparation of sodium acid phosphate has been well tolerated, led to therapeutic effects and increased the urinary excretion of phosphate.

\section{Acknowledgments}

We are grateful to Dr D. M. Burley of Ciba Ltd., Horsham, for supplies of Slow $\mathbf{P}$ and for the preliminary data on the solubility of the bonded tablet. We are indebted to Professors C. Gray and J. Anderson in the Departments of Medicine and Chemical Pathology for the provision of facilities for the estimations and to Dr E. R. Evans of Sandoz Ltd., for the provision of the porcine calcitonin used in this study. The balance study was carried out with facilities provided by the Department of Medicine supported by the British Empire Cancer Campaign.

\section{References}

Albright, F., Bauer, D., Clafin, D. \& Cokrill, J.R. (1932) Studies in parathyroid physiology. III. Effect of phosphate in clinical hyperparathyroidism. Journal of Clinical Investigation, 11, 411.

Anderson, J. \& Parsons, V. (1963) The tubular maximal resorptive rate for inorganic phosphate in normal subjects. Clinical Science, 25, 431.

Anderson, J., Bannister, D.W., Parsons, V. \& Tomlinson, R.W.S. (1967) Total urinary hydroxyproline excretion in osteomalacia. Calcified Tissue Research, 1, 183.

Coleman, C.M. \& STroje, R.C. (1965) Measurement of plasma in urine phosphate. Technicon Symposium Automation in Analytical Chemistry. New York.

DENT, C.E. (1962) Some problems of hyperparathyroidism. British Medical Journal, 2, 1495.

EdWARds, N.A., RusSEll, R.G.G. \& Hodgkinson, A. (1965) The effects of oral phosphate in patients with recurrent renal calculus. British Journal of Urology, 37, 370.

EISENBERG, E. (1968) Effects of varying phosphate intake in primary hyperparathyroidism. Journal of Clinical Endocrinology and Metabolism, 28, 651 .
Fiske, C.H. \& Subbarow, Y. (1925) The colorimetric determination of phosphorus. Journal of Biological Chemistry, 66, 375.

Fleish, E., Bisaz, S. \& CARE, A.D. (1964) Effect of orthophosphate on urinary pyrophosphate excretion and the prevention of urolithiasis. Lancet, i, 1065.

Foster, G.V., Joplin, G.F., Macintyre, I., Melvin, K.E.W. \& SLACK, E. (1966) Effect of thyrocalcitonin in man. Lancet, i, 107.

GoldSMITH, R.S. \& INGBAR, S.H. (1966) Inorganic phosphate treatment of hypercalcaemia of diverse etiologies. New England Journal of Medicine, 274, 1.

Goldsmith, R.S., Woodhouse, C.F., INGbaR, S.H. \& SEGAL, D. (1967) Effect of phosphate supplements in patients with fractures. Lancet, i, 687.

HIRSCH, P.F. \& COOPER, C.W. (1968) Parathyro.d Hormone and Thyrocalcitonin Symposium. The Mode of Action of Thyrocalcitonin, p. 381. Excerpta Medica, Amsterdam.

Massry, S.G., Mueller, E., Silverman, A.G. \& Kleeman, C.R. (1968) Inorganic phosphate treatment of hypercalcaemia. Archives of Internal Medicine, 121, 307.

Mills, J.N. \& Stanbury, S.W. (1955) Rhythmic diurnal variations in the behaviour of the human renal tubule. Acta Medica Scandinavica, Suppl. 307, 95.

Nagant, de Deuxchaisnes, C. \& KRANe, S.M. (1967) Treatment of adult phosphate diabetes and Fanconi Syndrome with neutral sodium phosphate. American Journal of Medicine, 43, 508.

Prockop, D.J. \& UDENFriend, S. (1960) A specific method for the analysis of hydroxyproline in tissues and urine. Analytical Biochemistry, 1, 228.

SMITH, R. \& Dick, M. (1968) Total urinary hydroxyproline in osteomalacia and the effect upon it of treatment with Vitamin D. Clinical Science, 34, 43.

Thalassinos, N. \& Joplin, G.F. (1968) Phosphate treatment of hypercalcaemia due to carcinoma. British Medical Journal, 2, 14.

Wilson, D.R. \& YENDT, E.R. (1963) Treatment of the adult Fanconi Syndrome with oral phosphate supplements and alkali. Report of two cases associated with nephrolithiasis. American Journal of Medicine, 35, 487.

WYNN, V. (1965) Potassium chloride and intestinal ulceration. Lancet, ii, 1241. 